\title{
Perceptions and Experiences of COVID-19 Vaccine Side-Effects Among Healthcare Workers in Southern Ethiopia: A Cross-Sectional Study
}

\author{
Bewunetu Zewude ${ }^{\prime}$ \\ Tewodros Habtegiorgis (iD) \\ Ashenafi Hizkeal ${ }^{1}$ \\ Tamirat Dela iD ${ }^{2}$ \\ Getahun Siraw (iD ${ }^{3}$ \\ 'Department of Sociology, College of \\ Social Sciences and Humanities, Wolaita \\ Sodo University, Wolaita Sodo town, \\ Ethiopia; ${ }^{2}$ Department of Civics and \\ Ethical Studies, College of Social Sciences \\ and Humanities, Wolaita Sodo University, \\ Wolaita Sodo town, Ethiopia; \\ ${ }^{3}$ Department of Sociology, College of \\ Social Sciences and Humanities, Dilla \\ University, Dilla town, Ethiopia
}

Background: We examined the perceptions of healthcare workers about the side-effects of COVID-19 vaccine and the types of side-effects they experienced in the post-vaccination period. Methods: An institutional-based cross-sectional survey research design was used in which a semi-structured questionnaire was distributed to collect quantitative data from healthcare workers in Southern Ethiopia that were selected on the basis of a multi-stage cluster sampling technique. After inserting the completed cases into SPSS software, descriptive statistical techniques, such as frequencies, percentages, charts and inferential statistical tool, particularly binary logistic regression analysis, were used to analyze and present the data.

Results: Majority (43.6\%) of respondents perceive that COVID-19 vaccine will have muscle pain around the injection site, followed by fever $(39.9 \%)$, problems of blood clots $(37.8 \%)$, headache $(35.6 \%)$, fatigue $(33.5 \%)$, and aching limbs $(16 \%)$. And $63.6 \%)$ of them reported that they have experienced muscle pain around the injection site after receiving the COVID19 vaccine, followed by fatigue (42\%), headache (37.2\%), fever (34.2\%), redness around the injection site $(21.6 \%)$, and swelling around the injection site $(17.8 \%)$. Moreover, $25 \%$ reported that the fear of potential side-effects of COVID-19 vaccine inhibited them from taking the vaccine. Above all, it is found that respondents' expectation of COVID-19 vaccine to have such serious side-effects is significantly associated to their educational status ( $\mathrm{OR}=$ 0.229 ; $\mathrm{P}<0.01$; 95\%C.I.: $0.080-0.651$ ).

Conclusion: While the expectations of most of the healthcare workers regarding the sideeffects of the vaccine are parallel to the normal reactions of the vaccine, a significant proportion of the study participants have reported that they perceive COVID-19 vaccine will have life-threatening side-effects. Such fears have also played a role in affecting vaccine uptake. Therefore, the Ministry of Health, and other concerned government bodies should create further awareness on COVID-19 vaccine and related safety issues.

Keywords: COVID-19, perception, side-effect, vaccine, healthcare worker

\section{Introduction}

Vaccination plays an important role in improving and maintaining public health. ${ }^{1-4}$ It helps to control the transmission of infectious diseases, though its success heavily relies on peoples' willingness to receive it. ${ }^{5}$ According to Smith et al, ${ }^{6}$ vaccine uptake can be influenced by various factors, including perceptions that it causes adverse effects, attitude towards vaccination, perceived susceptibility to illness, knowledge about the vaccine, social influences and trust in the health care profession, and having increased information about the vaccine. Nevertheless, the presence of vaccines alone does not
Correspondence: Bewunetu Zewude Email bewunetuzewude@gmail.com 
guarantee that people that are relatively more likely to be infected by COVID-19, as in the case of healthcare workers, are safe. Instead, the discovery of vaccine and its physical and social accessibility should be complemented with healthcare workers' willingness to be vaccinated. The findings of previously undertaken empirical studies, eg $^{7-12}$ reveal that healthcare workers have low level of willingness to take COVID-19 vaccine mainly because of safety concerns.

It is to be recalled that the challenges of vaccine development do not end once an effective vaccine is developed. ${ }^{11}$ A fundamental problem in public health is the doubt in the efficacy and safety of a vaccine, which may affect the efforts of containing the pandemic. ${ }^{12}$ Public attitude regarding the benefits and the risks of vaccination puts an emphasis on safety because vaccines are usually given to healthy populations who may receive no immediate health benefit. ${ }^{13}$ Since the developments of COVID-19 vaccine, there have always been rumors that the vaccines are linked to various postvaccination adverse effects (such as infertility) that continue to circulate and be debated on various social media sites. ${ }^{14}$ While empirical findings are lacking, several cases of death, after vaccination, are being announced through public sites and mass media, which bring chaos in the field and public doubts about the safety of vaccination. ${ }^{12}$ Rumors about the adverse side-effects of AstraZeneca, such as reports of blood clots, immune thrombocytopenia (ITP), low platelet counts, internal bleeding, cerebral venous thrombosis (CVT), have affected vaccination campaigns in several European countries. ${ }^{11,12}$ Such rumors would lead people to lose trust on the vaccine and cause problems with vaccine hesitancy. ${ }^{1}$ For instance, the results of national polls conducted in the United States of America in the periods prior to the distribution of the COVID-19 vaccine revealed that many people were hesitant to receive the vaccine. ${ }^{17}$

Understanding the various side-effects that vaccination might cause is important for the different parties involved in the process, including the person receiving the vaccine, the caregivers, and the healthcare professionals. ${ }^{13}$ An adverse event following immunization is any episode of a medical nature that occurs after the administration of a vaccine but is not necessarily caused by vaccination. ${ }^{18}$ Nevertheless, the safety profile of COVID-19 vaccine was characterized by short-term, mild-to-moderate pain at the injection site and that the incidence of serious adverse events was low among persons who received the vaccines. ${ }^{19,20}$ The approved COVID-19 vaccines are safe and that only $10 \%$ of participants suffered from severe side effects, while $39 \%$ and $21 \%$ of participants had moderate and mild side effects, respectively. ${ }^{14}$ Findings from previously undertaken studies on the side-effects of COVID-19 vaccine reveal mild-tomoderate side-effects. In fact, the severity of side effects among participants differed based on the type of COVID19 vaccine. ${ }^{14}$ For instance, Kadali et $\mathrm{al}^{21}$ studied the side effects of the BNT162b2 vaccine among healthcare workers and found that soreness, fatigue, myalgia, headache, chills, fever, joint pain, nausea, muscle spasm, sweating, dizziness, flushing, feelings of relief, brain fogging, anorexia, localized swelling, decreased sleep quality, itching, tingling, diarrhea, nasal stuffiness and palpitations were the commonly reported symptoms reported after receiving the vaccine. Above all, Klugar et $\mathrm{al}^{22}$ found that injection site pain (75.6\%) was the most common local side effect, and headache/fatigue (53.6\%), muscle pain (33.2\%), malaise (25\%), chills (23\%), and joint pain $(21.2 \%)$ were the most common systemic side effects. Currently, the only major risk identified is anaphylaxis. ${ }^{21}$ According to Kaur et al, ${ }^{23}$ common adverse events observed with the vaccine were tachycardia, flushing, hypertension, hypotension, and peripheral coldness.

For the first time since the outbreak of the COVID-19 pandemic, Ethiopia received about 2.2 million AstraZeneca COVID-19 vaccines in March, 2021. ${ }^{24}$ And sources reveal that close to 1.9 million people in Ethiopia have already been vaccinated for the first dose of AstraZeneca. ${ }^{25}$ The present study was undertaken during a period in Ethiopia where over two million doses of COVID-19 vaccine (AstraZeneca) have already been shipped and healthcare workers and elderlies with chronic illnesses have started to receive the second round of the vaccine in the major towns of the country and others are waiting to receive the same. Given the widely held rumors associated to the COVID-19 vaccine in general and that of AstraZeneca in particular ${ }^{15,16}$ recipients' perception about the possible side effects of the vaccine is expected to be negative. Therefore, promoting vaccine confidence by disseminating empirically supported information in the way it addresses the commonly held reasons not to be vaccinated is important to prevent the spread of COVID-19 pandemic. ${ }^{17}$ Therefore, the purpose of this research was to assess the perceptions held and the experiences witnessed by healthcare workers regarding the side effects of COVID-19 vaccine in Southern Ethiopia.

\section{Materials and Methods Research Design}

Through quantitative research approach, a cross-sectional study was conducted in which data were gathered from a sample of healthcare workers in Southern Ethiopia. 


\section{Research Site and Selection of}

\section{Participants}

This study was conducted during the period in which part of the population "most at risk of infection to COVID-19" have started to take the second round of COVID-19 vaccine, while most others are waiting for the supply. Therefore, the target populations of the present research were all people in Ethiopia that have either already received the first/second-round of [AstraZeneca] COVID19 vaccine or have the opportunity to receive it because of their susceptibility to be infected by the pandemic and as a result, designated by the Ministry of Health as deserving priority in accessing the vaccine. Unfortunately, it is only healthcare workers and a few elderly people with chronic illnesses that have got the chance to be vaccinated through increased access to the vaccine, including Johnson and Johnson, seems to emerge in the near future with continued efforts from the side of the government and the generosity of the international partners. With the poor client's basic information archival experiences of healthcare facilities in the study area, tracing the addresses of the other groups who have taken the vaccine is hardly possible for the researchers. Consequently, the survey populations of the present study are all healthcare workers in Southern Ethiopia, who have taken the first/second- round of COVID-19 vaccine, including those that are likely to receive the vaccine. A multi-stage cluster sampling technique was used to draw a sample of healthcare workers in the study area. In order to determine the sample size, the researchers applied Cochran's (1977) formula for calculating sample size of unknown population as:

$n=\frac{z^{2} \times p(1-p)}{\mathrm{e}^{2}}=1.96^{2} \times 0.5(1-0.5) / 0.05^{2}=384$

Then, the final sample units were chosen on the basis of probability proportionate to size sampling technique. The major inclusion criteria for participating in the study were being a healthcare worker actively serving in any of healthcare facilities in Southern Ethiopia during the time of the study and willingness to be included in the survey.

\section{Research Method}

Survey method was used to generate data where a semistructured questionnaire was randomly distributed to a sample of healthcare workers in Southern Ethiopia. Once we prepared the questionnaire, we gave it to two editors from which one is professional in linguistics and the other in public health. Before the final questionnaire was duplicated and distributed, we have tested its validity on 30 healthcare workers in the study area. After receiving the feedback and making all the necessary corrections, we duplicated the questionnaire proportional to the calculated sample size after considering 5\% non-response rate (403 samples). Finally, after obtaining consent, trained data collectors have distributed the questionnaires to the healthcare workers.

\section{Instrumentation}

A self-administered questionnaire was used to collect data from the healthcare workers selected to participate in the research. While most of the items included in the tool were developed by the researchers, only some elements were taken from relevant studies undertaken by Hatmal et al ${ }^{14}$ and Zewude et $\mathrm{al}^{26}$ and adopted for the purpose at hand. The questionnaire mainly consists of two sections. The first section aims to collect the socio-demographic background of the respondents and it includes questions such as age, sex, marital status, educational status, ownership of the healthcare organization in which respondents are working during the time of the survey, and their occupational status. In addition, the section also contains questions that help to measure healthcare workers' perception of COVID-19 and their previous history of infection, such as: "Do you think that you can be infected by COVID19?", "Do you think that you are likely to die if you get infected by COVID-19?", "Do you believe that COVID-19 vaccine is effective in preventing the transmission of COVID-19?", and "Have you ever been infected by COVID-19?" all with response categories of "yes" and "no".

The second section of the questionnaire mainly aims to gather data pertaining to the perception/expectation and experiences about the side effects of COVID-19 vaccine. It includes questions such as: 1) "Have you ever expected that COVID-19 vaccine will have serious and life-threatening side effects?" with "yes" or "no" response categories, 2) "Which of the following side effects of COVID-19 vaccine were you expecting?" with response categories of "muscle pain around injection site", "swelling", "flushing", "fatigue", "fever", "headache", "nasal stiffness", "irregular heartbeats", "depression" and other types possible COVID-19 vaccine reactions, 3) "Did your expectation/fear inhibit you from receiving the vaccine?" with response categories of "yes" and "no", 4) "What is your source of information regarding COVID-19 
vaccine?" with response categories of "Local public electronic media (EBC, FBC, radio, etc.)", "Local print media (newspaper, magazine, etc.)", "International media outlets (BBC, CNN, etc.)", "Social media outlets (Facebook, Twitter, etc.)", "Social network platforms (colleagues, relatives, etc.)", "Medical journals and other scientific websites", 5) "If you have already received COVID-19 vaccine, which of the following side effects did you face in the first 3 days after vaccination?" with response categories of "muscle pain around injection site", "swelling", "flushing", "fatigue", "fever", "headache", "nasal stiffness", "irregular heartbeats", "depression" and other types possible COVID-19 vaccine reactions, 6) "How severe/painful were the side-effects that you experienced after vaccination?" with response categories of "no feeling of pain at all", "mild", "moderate", "severe", and "highly severe".

\section{Method of Data Analysis}

The data were first checked for completeness. Questionnaires that were found to be correctly filled were inserted into the SPSS software. Then, data analysis was conducted using statistical techniques, including percentages, frequency distributions, and logistic regression analysis. Descriptive statistical techniques were used to analyze and present issues, such as the socio-demographic characteristics of respondents, perceptions and experiences of healthcare workers regarding the side-effects of COVID-19 vaccine, their vaccination history, reasons for not receiving the vaccine, the severity of the side-effects and the length of period it took for them to recover from the side-effects, among other things. Inferential statistical technique, particularly binary logistic regression analysis, was carried out to test the factors associated to healthcare workers' perception that COVID-19 vaccine has life-threatening side-effects. Accordingly, the variables having a significance level of P-value less than 0.05 were considered to have been associated with the dependent variable.

\section{Results}

Table 1 presents data pertaining to the socio-demographic characteristics of respondents. It is shown that $52.9 \%$ of respondents are males and $47.1 \%$ are females. In addition, the mean age of respondents has been found to be 30.31 $(\mathrm{SD}=6.03)$. Majority $(59.8 \%)$ of the healthcare workers participating in the survey are married, followed by the never married (38.5\%). The educational status of respondents reveals that most $(69 \%)$ of them are BA/BSc degree holders, $18.7 \%$ college diploma completes, and $8 \%$ are MA/MSc degree graduates. Moreover, it is found that $44 \%$ of healthcare workers participated in the survey are nurses, followed by $18.7 \%$ health officers, $10.9 \%$ midwives, and $9.2 \%$ are medical doctors. As far as the ownership of the healthcare facilities in which respondents are working during the time of the survey is concerned, $50 \%$ of them work in public healthcare facilities, $45.4 \%$ belong to the private ones, and the remaining $4.6 \%$ work in healthcare organizations established for charity purposes. Furthermore, $56.3 \%$ of respondents perceive that they can be infected by COVID-19, while $63.5 \%$ of them think that they are not likely to die if infected by COVID-19. 53.2\% of healthcare workers in the study area believe that COVID-19 vaccine is effective in preventing the transmission of COVID-19. The data also indicated that $54.3 \%$ of respondents disclosed that they have never been infected by COVID-19, 32.5\% are not sure, and $13.2 \%$ of them reported that they have ever been infected. Above all, the vaccination history of the research participants shows that $50.6 \%$ of them are fully vaccinated, $27.3 \%$ have received only the first dose, while $22.1 \%$ are not vaccinated at all.

According to the data presented in Table 2, it is shown that most $(50.5 \%)$ of the healthcare workers participated in the survey received only the first dose of COVID-19 vaccine due to the reason that they did not get the opportunity to be vaccinated, followed by concern over the safety or side-effects of the vaccine $(18.3 \%)$, which respondents are not comfortable with the first-dose of the vaccine $(15.1 \%)$, and doubts about the effectiveness of the vaccine (10.8\%). In addition, it is also found that $34.7 \%$ of the respondents reported that they did not receive both doses of the vaccine due to concern over the safety or side effects of the vaccine, $30.7 \%$ of them answered that it is because of the lack of opportunity, doubts about the effectiveness of the vaccine in preventing infection $(20 \%)$, the trust over the adequacy of one's natural immunity $(16 \%)$, and reasons related to belief or religion $(8 \%)$ have been found to be the other reasons.

Data presented in Table 3 shows the frequency and percentage distributions of healthcare workers pertaining to their perceptions about the side-effects of COVID-19 vaccine. Accordingly, it is found that majority $(43.6 \%)$ of respondents perceive that COVID-19 vaccine will have muscle pain around the injection site, followed by fever $(39.9 \%)$, problems of blood clots (37.8\%), headache (35.6\%), fatigue $(33.5 \%)$, and aching limbs (16\%). As far as the sources 
Table I Socio-Demographic Characteristics of Respondents

\begin{tabular}{|c|c|c|}
\hline Variables & Categories & Frequency (\%) \\
\hline \multirow[t]{2}{*}{ Sex } & Male & $184(52.9 \%)$ \\
\hline & Female & $164(47.1 \%)$ \\
\hline \multirow[t]{4}{*}{ Marital Status } & Never married & $134(38.5 \%)$ \\
\hline & Married & $208(59.8 \%)$ \\
\hline & Divorced & $4(1.1 \%)$ \\
\hline & Widowed & $2(0.6 \%)$ \\
\hline \multirow[t]{5}{*}{ Educational Status } & Primary level (I-8) & $7(2 \%)$ \\
\hline & Secondary level (9-12) & $8(2.3 \%)$ \\
\hline & College diploma & $65(18.7 \%)$ \\
\hline & BA/BSc degree & $240(69 \%)$ \\
\hline & MA/MSc degree and above & $28(8 \%)$ \\
\hline \multirow[t]{8}{*}{ Occupational Status } & Medical doctor & $32(9.2 \%)$ \\
\hline & Health officer & $62(17.8 \%)$ \\
\hline & $\begin{array}{l}\text { Administrative } \\
\text { (managerial) staff }\end{array}$ & $8(2.3 \%)$ \\
\hline & Nurse & $153(44 \%)$ \\
\hline & Laboratory technician & $16(4.6 \%)$ \\
\hline & Pharmacist (druggist) & $15(4.3 \%)$ \\
\hline & Midwife & $38(10.9 \%)$ \\
\hline & Other & $24(6.9 \%)$ \\
\hline \multirow[t]{3}{*}{ Ownership of the organization Where respondents work } & Public & $174(50 \%)$ \\
\hline & Private & $158(45.4 \%)$ \\
\hline & Charity & $16(4.6 \%)$ \\
\hline \multirow[t]{2}{*}{ Do you think that you can be infected by COVID-19? } & Yes & $196(56.3 \%)$ \\
\hline & No & $152(43.7 \%)$ \\
\hline \multirow[t]{2}{*}{ Do you think that you are likely to die if infected by COVID-19? } & Yes & $127(36.5 \%)$ \\
\hline & No & $221(63.5 \%)$ \\
\hline \multirow[t]{2}{*}{ Do you believe that COVID-19 vaccine is effective in preventing the transmission of COVID-19? } & Yes & $163(46.8 \%)$ \\
\hline & No & $185(53.2 \%)$ \\
\hline \multirow[t]{3}{*}{ Have you ever been infected by COVID-19? } & Yes & $46(13.2 \%)$ \\
\hline & No & $189(54.3 \%)$ \\
\hline & Not sure & $113(32.5 \%)$ \\
\hline \multirow[t]{4}{*}{ Respondents' COVID-19 vaccination history } & $\begin{array}{l}\text { Completed (received full } \\
\text { dose) }\end{array}$ & $176(50.6 \%)$ \\
\hline & $\begin{array}{l}\text { Default (received only the } \\
\text { first dose) }\end{array}$ & $95(27.3 \%)$ \\
\hline & Not vaccinated at all & $77(22.1 \%)$ \\
\hline & Total & $348(100 \%)$ \\
\hline
\end{tabular}


Table 2 Reasons for Defaulting and Not Receiving the Full Dose of COVID-19 Vaccine

\begin{tabular}{|c|c|c|c|c|}
\hline & & \multicolumn{2}{|c|}{ Responses } & \multirow{2}{*}{$\begin{array}{l}\text { Percent of } \\
\text { Cases }\end{array}$} \\
\hline & & $\mathbf{N}$ & Percent & \\
\hline \multirow[t]{14}{*}{ Reasons for defaulting } & Did not get the opportunity to be vaccinated (supply side factor) & 47 & $39.8 \%$ & $50.5 \%$ \\
\hline & $\begin{array}{l}\text { I believe that the first dose of Covid-19 vaccine is sufficient to } \\
\text { prevent infection }\end{array}$ & 5 & $4.2 \%$ & $5.4 \%$ \\
\hline & I am concerned about the safety and/or the side effects & 17 & $14.4 \%$ & $18.3 \%$ \\
\hline & I was not comfortable with the first dose of Covid-19 vaccine & 14 & $11.9 \%$ & $15.1 \%$ \\
\hline & I believe that I have adequate natural immunity & 3 & $2.5 \%$ & $3.2 \%$ \\
\hline & I am concerned because I do not think the vaccine will be effective & 10 & $8.5 \%$ & $10.8 \%$ \\
\hline & $\begin{array}{l}\text { I believe that I can easily withstand the illness if infected by the } \\
\text { disease }\end{array}$ & 2 & $1.7 \%$ & $2.2 \%$ \\
\hline & $\begin{array}{l}\text { I do not think I will need the vaccine due to previous infection, } \\
\text { health status or age }\end{array}$ & 2 & $1.7 \%$ & $2.2 \%$ \\
\hline & I am against vaccines in general & I & $0.8 \%$ & $1.1 \%$ \\
\hline & Lack of adequate information & 2 & $1.7 \%$ & $2.2 \%$ \\
\hline & $\begin{array}{l}\text { I believe that other non-vaccine preventive mechanisms are } \\
\text { sufficient }\end{array}$ & 3 & $2.5 \%$ & $3.2 \%$ \\
\hline & Covid-19 is not that serious concern in my work or residential area & I & $0.8 \%$ & $1.1 \%$ \\
\hline & No reason & I & $0.8 \%$ & $1.1 \%$ \\
\hline & Other reasons & 10 & $8.5 \%$ & $10.8 \%$ \\
\hline Total & & 118 & $100.0 \%$ & $126.9 \%$ \\
\hline \multirow{11}{*}{$\begin{array}{l}\text { Reasons for not Receiving the } \\
\text { vaccine at all }\end{array}$} & Did not get the opportunity to be vaccinated (supply side factor) & 23 & $23.2 \%$ & $30.7 \%$ \\
\hline & I am concerned about the safety and/or the side effects & 26 & $26.3 \%$ & $34.7 \%$ \\
\hline & I am concerned because I do not think the vaccine will be effective & 15 & $15.2 \%$ & $20.0 \%$ \\
\hline & I believe that I have adequate natural immunity & 12 & $12.1 \%$ & $16.0 \%$ \\
\hline & I believe that I am not at risk of being infected by Covid- 19 & I & $1.0 \%$ & $1.3 \%$ \\
\hline & $\begin{array}{l}\text { I believe that I can easily withstand the illness if infected by the } \\
\text { disease }\end{array}$ & 4 & $4.0 \%$ & $5.3 \%$ \\
\hline & I am against vaccines in general & 3 & $3.0 \%$ & $4.0 \%$ \\
\hline & Lack of adequate information about it & 5 & $5.1 \%$ & $6.7 \%$ \\
\hline & Reasons related to belief/religion & 6 & $6.1 \%$ & $8.0 \%$ \\
\hline & $\begin{array}{l}\text { I believe that other non-vaccine preventive mechanisms are } \\
\text { sufficient }\end{array}$ & 3 & $3.0 \%$ & $4.0 \%$ \\
\hline & I do not believe that Covid-19 really exists & I & $1.0 \%$ & $1.3 \%$ \\
\hline Total & & 99 & $100.0 \%$ & $132.0 \%$ \\
\hline
\end{tabular}

of information about COVID-19 vaccine is concerned, it is shown that most $(65.2 \%)$ of respondents rely on local public electronic media outlets, $46.8 \%$ on social media sources, and $41.4 \%$ of them have been using international media outlets for information regarding COVID-19 vaccine. 
Table 3 Frequency Distribution of Responses Regarding Perceptions About the Side-Effects of COVID-19 Vaccine

\begin{tabular}{|c|c|c|c|c|}
\hline & & \multicolumn{2}{|c|}{ Responses } & \multirow[t]{2}{*}{ Percent of Cases } \\
\hline & & $\mathbf{N}$ & Percent & \\
\hline \multirow{28}{*}{$\begin{array}{l}\text { Perceptions/expectations of } \\
\text { CIVID-19 Vaccine Side-effects }\end{array}$} & Muscle pain around the injection site & 82 & $11.9 \%$ & $43.6 \%$ \\
\hline & Swelling around the injection site & 29 & $4.2 \%$ & $15.4 \%$ \\
\hline & Redness/flushing around the injection site & 27 & $3.9 \%$ & $14.4 \%$ \\
\hline & Fatigue & 63 & $9.1 \%$ & $33.5 \%$ \\
\hline & Fever & 75 & $10.9 \%$ & $39.9 \%$ \\
\hline & Headache & 67 & $9.7 \%$ & $35.6 \%$ \\
\hline & Nasal stiffness & 6 & $0.9 \%$ & $3.2 \%$ \\
\hline & Irregular heartbeats & 10 & $1.4 \%$ & $5.3 \%$ \\
\hline & Aching limbs & 30 & $4.3 \%$ & $16.0 \%$ \\
\hline & Depression & 25 & $3.6 \%$ & $13.3 \%$ \\
\hline & Bleeding gums & 5 & $0.7 \%$ & $2.7 \%$ \\
\hline & Allergic shocks & 24 & $3.5 \%$ & $12.8 \%$ \\
\hline & Problems of blood clots & 71 & $10.3 \%$ & $37.8 \%$ \\
\hline & Internal bleeding & 11 & $1.6 \%$ & $5.9 \%$ \\
\hline & Sleepiness and laziness & 28 & $4.1 \%$ & $14.9 \%$ \\
\hline & Abnormal blood pressure & 9 & $1.3 \%$ & $4.8 \%$ \\
\hline & Nausea & 26 & $3.8 \%$ & $13.8 \%$ \\
\hline & Abdominal pain & 11 & $1.6 \%$ & $5.9 \%$ \\
\hline & Decreased sleep quality & 11 & $1.6 \%$ & $5.9 \%$ \\
\hline & Chest pain & 9 & $1.3 \%$ & $4.8 \%$ \\
\hline & Diarrhea & 8 & $1.2 \%$ & $4.3 \%$ \\
\hline & Vomiting & 5 & $0.7 \%$ & $2.7 \%$ \\
\hline & Chills & 26 & $3.8 \%$ & $13.8 \%$ \\
\hline & Sore or dry throat & 6 & $0.9 \%$ & $3.2 \%$ \\
\hline & Dizziness & 5 & $0.7 \%$ & $2.7 \%$ \\
\hline & Infertility & 7 & $1.0 \%$ & $3.7 \%$ \\
\hline & Other serious reactions & 7 & $1.0 \%$ & $3.7 \%$ \\
\hline & Death & 8 & $1.2 \%$ & $4.3 \%$ \\
\hline Total & & 691 & $100.0 \%$ & $367.6 \%$ \\
\hline
\end{tabular}


Table 3 (Continued).

\begin{tabular}{|c|c|c|c|c|}
\hline & & \multicolumn{2}{|c|}{ Responses } & \multirow[t]{2}{*}{ Percent of Cases } \\
\hline & & $\mathbf{N}$ & Percent & \\
\hline \multirow[t]{7}{*}{$\begin{array}{l}\text { Sources of Information } \\
\text { about COVID-19 Vaccine }\end{array}$} & $\begin{array}{l}\text { Local public electronic media ( } E B C, F B C \text {, radio, } \\
\text { etc.) }\end{array}$ & 227 & $29.0 \%$ & $65.2 \%$ \\
\hline & Local print media (newspaper, magazine, etc.) & 49 & $6.3 \%$ & $14.1 \%$ \\
\hline & International media outlets (BBC, $\mathrm{CNN}$, etc.) & 144 & $18.4 \%$ & $41.4 \%$ \\
\hline & Social media outlets (Facebook, Twitter, etc.) & 163 & $20.8 \%$ & $46.8 \%$ \\
\hline & $\begin{array}{l}\text { Social network platforms (colleagues, relatives, } \\
\text { etc) }\end{array}$ & 99 & $12.7 \%$ & $28.4 \%$ \\
\hline & Medical journals and other scientific websites & 83 & $10.6 \%$ & $23.9 \%$ \\
\hline & Others & 17 & $2.2 \%$ & $4.9 \%$ \\
\hline Total & & 782 & $100.0 \%$ & $224.7 \%$ \\
\hline \multirow{4}{*}{$\begin{array}{l}\text { Expectation of serious side- } \\
\text { effects and its effect }\end{array}$} & \multirow{2}{*}{$\begin{array}{l}\text { Have you ever expected that COVID-19 vaccine } \\
\text { will have Serious and life-threatening side- } \\
\text { effects? }\end{array}$} & Yes & $168(48.3 \%)$ & \\
\hline & & No & $180(51.7 \%)$ & \\
\hline & \multirow{2}{*}{$\begin{array}{l}\text { Did your expectation/fear inhibit you from } \\
\text { receiving the vaccine? }\end{array}$} & Yes & $87(25 \%)$ & \\
\hline & & No & $26 \mid(75 \%)$ & \\
\hline Total & & & $348(100 \%)$ & \\
\hline
\end{tabular}

Above all, $48.3 \%$ of healthcare workers participated in the study disclosed that they have ever expected that COVID-19 vaccine will have serious and life-threatening side-effects while $51.7 \%$ reported that they have never expected such side-effects of the vaccine. In addition, $75 \%$ of the respondents answered that the fear of sideeffects of COVID-19 vaccine have not inhibited them from receiving the vaccine and $25 \%$ reported that the fear of the potential side-effects of COVID-19 vaccine inhibited them from taking the vaccine.

\section{Experiences of COVID-I 9 Vaccine Side-Effects}

Data presented in Table 4 reveals that majority (63.6\%) of the healthcare workers participated in the survey reported that they have experienced muscle pain around the injection site after receiving the COVID-19 vaccine, followed by those who disclosed to have experienced fatigue (42\%), headache $(37.2 \%)$, fever $(34.2 \%)$, redness around the injection site $(21.6 \%)$, and swelling around the injection site $(17.8 \%)$. Furthermore, it is also indicated that only $3.3 \%$ of the research participants have reported that they have experienced other side-effects that can be labeled as more serious than the types of side-effects mentioned in the table. In addition, the data in Table 3 also present the types of treatments research participants received after experiencing the side-effects of COVID-19 vaccine. Accordingly, most (38.8\%) of the respondents reported to have taken rest, followed by those who have done nothing (38.4\%), took anti-pain (35.1\%), and those who have consulted a physician $(8.6 \%)$.

Data presented in Figure 1 shows that $17.5 \%$ of healthcare workers participated in the survey disclosed that the side-effects/reactions of the vaccine lasted for 2 days, while $17 \%$ and $17 \%$ of them reported that it lasted for less than a day and for one day, respectively. In addition, $13.2 \%$ of respondents reported 3 days and $5.7 \%$ answered 7 days and above.

As shown in Figure 2, 36.2\% of the study participants reported that the severity of the side-effects of COVID-19 vaccine was mild, followed by $30.5 \%$ who disclosed that it was moderate, 5.7 and reported severe, and $1.1 \%$ said it was highly severe. Moreover, $3.7 \%$ of respondents answered to have experienced no feeling of pain at all. 
Table 4 Experiences of COVID-19 Vaccine Side-Effects and Treatments Received

\begin{tabular}{|c|c|c|c|c|}
\hline & & \multicolumn{2}{|c|}{ Responses } & \multirow[t]{2}{*}{ Percent of Cases } \\
\hline & & $\mathbf{N}$ & Percent & \\
\hline \multirow{26}{*}{$\begin{array}{l}\text { Experience of COVID-19 Vaccine } \\
\text { Side-effects }\end{array}$} & Muscle pain around the injection site & $|7|$ & $19.7 \%$ & $63.6 \%$ \\
\hline & Swelling around the injection site & 48 & $5.5 \%$ & $17.8 \%$ \\
\hline & Redness/flushing around the injection site & 58 & $6.7 \%$ & $21.6 \%$ \\
\hline & Fatigue & 113 & $13.0 \%$ & $42.0 \%$ \\
\hline & Fever & 92 & $10.6 \%$ & $34.2 \%$ \\
\hline & Headache & 100 & $11.5 \%$ & $37.2 \%$ \\
\hline & Nasal stiffness & II & $1.3 \%$ & $4.1 \%$ \\
\hline & Irregular heartbeats & 8 & $0.9 \%$ & $3.0 \%$ \\
\hline & Aching limbs & 48 & $5.5 \%$ & $17.8 \%$ \\
\hline & Depression & 33 & $3.8 \%$ & $12.3 \%$ \\
\hline & Allergic shocks & 5 & $0.6 \%$ & $1.9 \%$ \\
\hline & Problems of blood clots & 5 & $0.6 \%$ & $1.9 \%$ \\
\hline & Internal bleeding & I & $0.1 \%$ & $0.4 \%$ \\
\hline & Sleepiness and laziness & 20 & $2.3 \%$ & $7.4 \%$ \\
\hline & Abnormal blood pressure & 2 & $0.2 \%$ & $0.7 \%$ \\
\hline & Nausea & 39 & $4.5 \%$ & $14.5 \%$ \\
\hline & Abdominal pain & 13 & $1.5 \%$ & $4.8 \%$ \\
\hline & Decreased sleep quality & 26 & $3.0 \%$ & $9.7 \%$ \\
\hline & Chest pain & 8 & $0.9 \%$ & $3.0 \%$ \\
\hline & Diarrhea & 10 & $1.2 \%$ & $3.7 \%$ \\
\hline & Vomiting & 2 & $0.2 \%$ & $0.7 \%$ \\
\hline & Chills & 31 & $3.6 \%$ & $11.5 \%$ \\
\hline & Sore or dry throat & 8 & $0.9 \%$ & $3.0 \%$ \\
\hline & Dizziness & 7 & $0.8 \%$ & $2.6 \%$ \\
\hline & Other serious reactions & 9 & $1.0 \%$ & $3.3 \%$ \\
\hline & Total & 868 & $100.0 \%$ & $322.7 \%$ \\
\hline \multirow{7}{*}{$\begin{array}{l}\text { Treatments made after the side- } \\
\text { effects }\end{array}$} & Nothing & 103 & $30.5 \%$ & $38.4 \%$ \\
\hline & Took a rest/slept & 104 & $30.8 \%$ & $38.8 \%$ \\
\hline & Took anti-pain & 94 & $27.8 \%$ & $35.1 \%$ \\
\hline & Consulted a physician & 23 & $6.8 \%$ & $8.6 \%$ \\
\hline & Traditional medical treatment & 9 & $2.7 \%$ & $3.4 \%$ \\
\hline & Others & 5 & $1.5 \%$ & $1.9 \%$ \\
\hline & Total & 338 & $100.0 \%$ & $126.1 \%$ \\
\hline
\end{tabular}




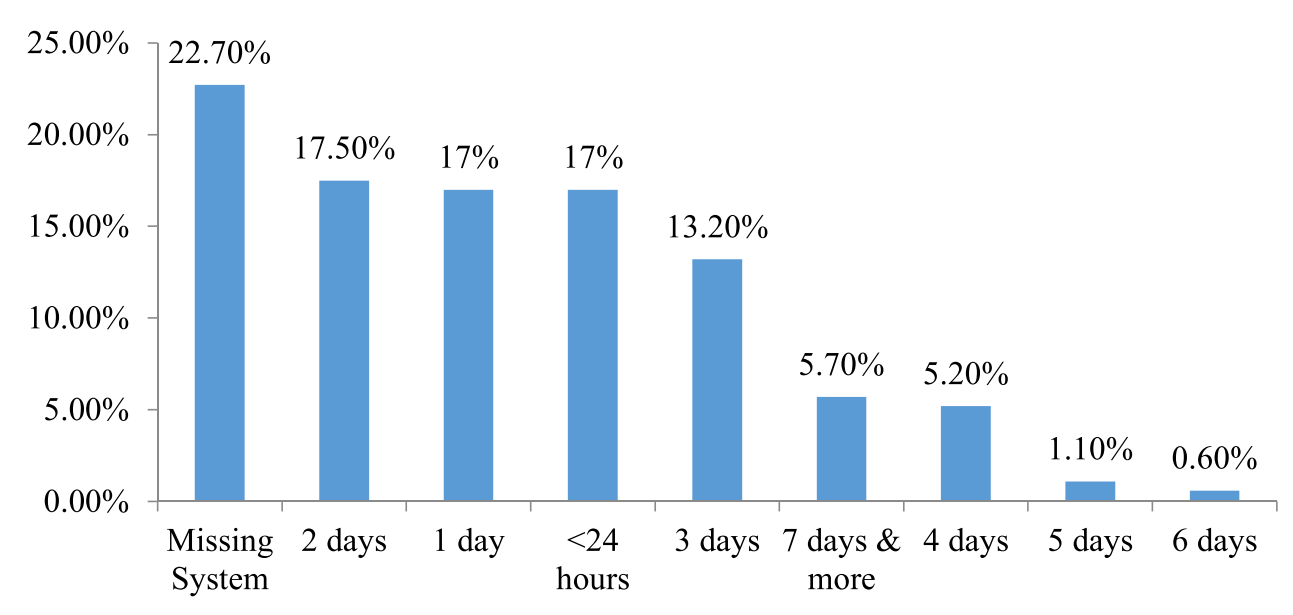

Figure I For how long did the side effects of COVID-19 vaccine last?

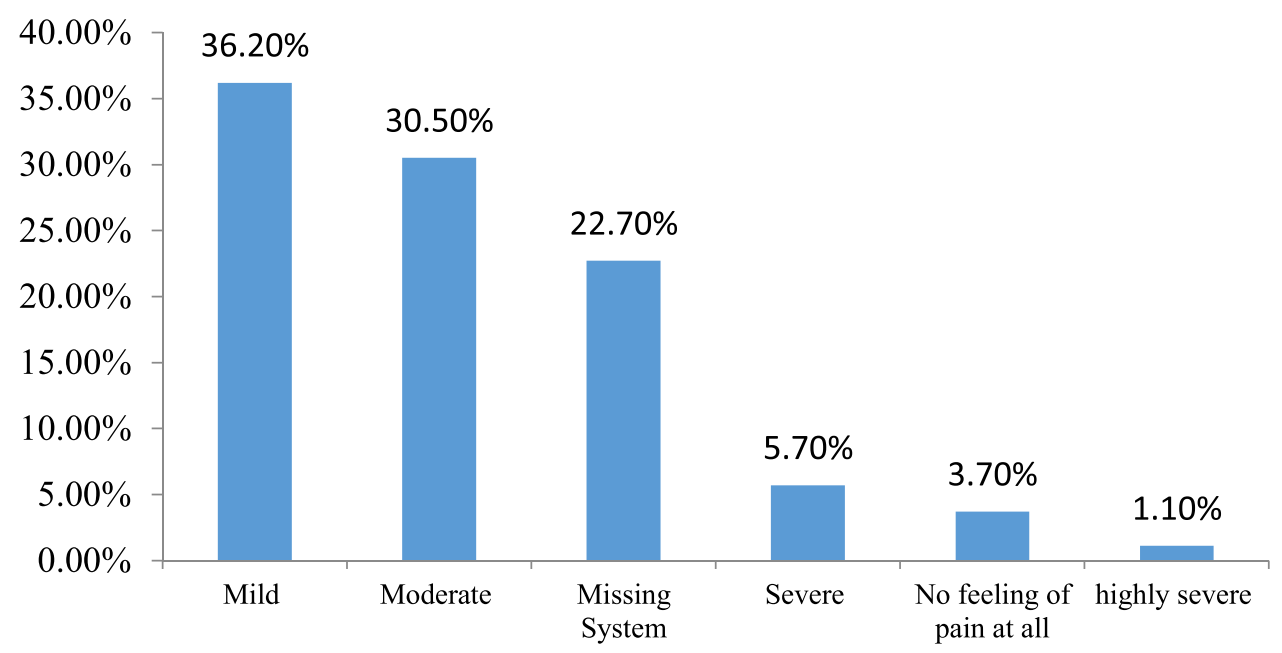

Figure $\mathbf{2}$ How severe/painful were the side-effects that you experienced after vaccination?

Data from Figure 3 present the percentage distribution of research participants who have been infected by COVID-19 after being vaccinated. Accordingly, it is found that $4 \%$ of the respondents reported to have ever been infected by COVID-19 after vaccination, 39.9\% replied no, while $33.3 \%$ are not sure about it.

The binary logistic regression data presented in Table 5 shows the association between respondents' socio-demographic data and their perception/expectation that COVID19 vaccine will have serious and life-threatening sideeffects. It is found that respondents' expectation of COVID-19 vaccine to have such serious side-effects is significantly associated to their educational status (OR = $0.229 ; \mathrm{P}<0.01 ; 95 \%$ C.I.: $0.080-0.651)$. Accordingly, healthcare workers' perception that COVID-19 vaccine will have life-threatening side-effects decreases with increasing educational status. Furthermore, other socio- demographic characteristics (sex, age, marital status, occupation, history of vaccination, history of COVID-19 infection, and perception regarding COVID-19) of the respondents are not significantly associated with their perception that COVID-19 vaccine will have serious sideeffects.

\section{Discussion}

Healthcare workers are facing an increasing threat as a result of confronting COVID-19 pandemic. ${ }^{26}$ COVID-19 has become one of the major causes of death, which has still continued to claim the lives of healthcare professionals worldwide ${ }^{27}$ most of whom are forced to work under circumstances where there are acute shortages of personal protective materials. ${ }^{28}$ The innovation of vaccination, no doubt, would help to maintain public health and safety $^{1-4}$ if the necessary activities of recipients' level of 


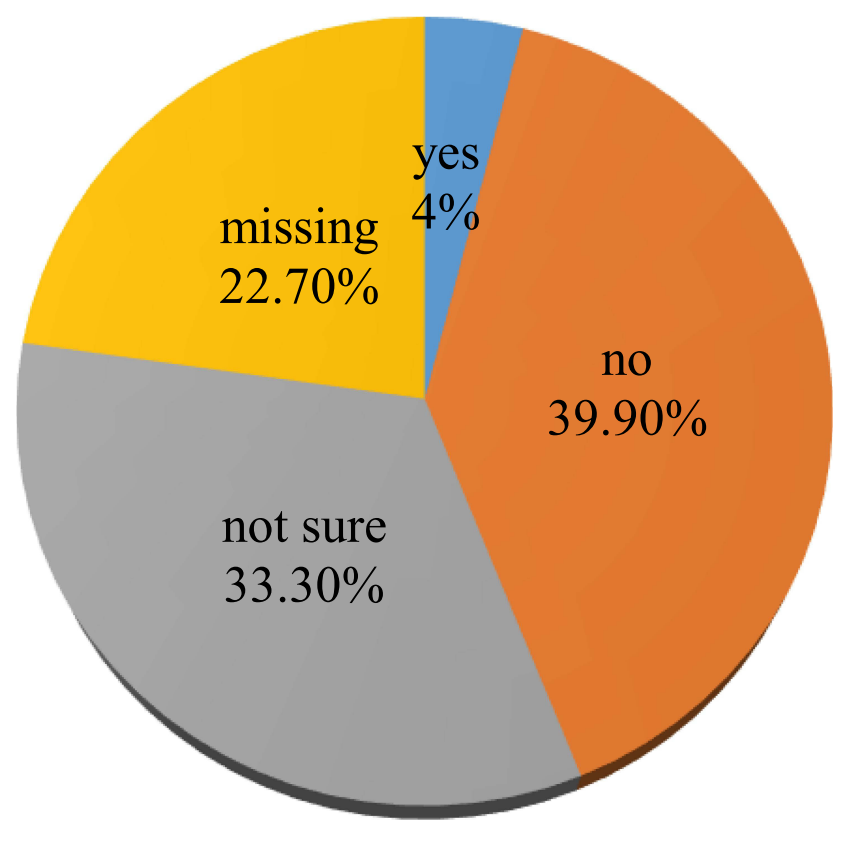

Figure 3 Have you ever been infected by COVID-19 after receiving the CIVID-19 vaccine?

awareness is raised in a way they become not hesitant to receive the vaccine. It is to be recalled that the challenges of vaccine development do not end once an effective vaccine is developed. ${ }^{1}$ A fundamental problem in public health is the suspicion in the efficacy and safety of a vaccine, and campaigns against vaccines in several countries worldwide are raising concerns about how this pandemic will be defeated. ${ }^{12}$ Since the developments of COVID-19 vaccine, there have always been rumors that the vaccines are linked to various post-vaccination adverse effects. ${ }^{14}$ Understanding the range of symptoms that vaccination might cause is important for the person receiving the vaccine, for caregivers/decision-makers, and for the healthcare professionals. ${ }^{13}$ The purpose of this research was to examine the perceptions of healthcare workers in Southern Ethiopia about the side-effects of COVID-19 vaccine. Quantitative data were collected using a survey method, inserted into the SPSS software, and analyzed using both descriptive and inferential statistical techniques.

The results of the present research revealed that most $(50.5 \%)$ of the healthcare workers participated in the survey received only the first dose of COVID-19 vaccine due to the reason that they did not get the opportunity to be vaccinated, followed by concern over the safety or sideeffects of the vaccine $(18.3 \%)$, that respondents are not comfortable with the first-dose of the vaccine (15.1\%), and doubts about the effectiveness of the vaccine $(10.8 \%)$. Moreover, the reasons for not getting fully vaccinated at all are concern over the safety or side effects of the vaccine, the lack of opportunity, doubts about the effectiveness of the vaccine in preventing infection, the trust over the adequacy of one's natural immunity, and reasons related to belief or religion. Related to the findings of the present study, Roy et $\mathrm{al}^{10}$ found that the main reasons for the lack of willingness to be vaccinated are safety issues and concerns over the clinical trial's exclusion of specific groups. Furthermore, Pataka et $\mathrm{al}^{29}$ found that the rate of acceptance of COVID-19 vaccine was higher among healthcare professionals working with COVID-19 patients and among physicians compared with nurses and other healthcare professionals. According to Unroe et al, ${ }^{30}$ concern about the side effects was the primary reason for the lack of intention to get vaccinated. Above all, Zewude et $\mathrm{al}^{26}$ found that the main reason for most respondents' hesitancy to take the vaccine is the concern over the safety and/or the side effects of the vaccine, followed by doubt about the vaccine's effectiveness, and lack of adequate information. Safety, effectiveness, and speed of development/approval were found to be the most common concerns regarding COVID-19 vaccination. ${ }^{5}$ Cerda et al $^{31}$ revealed that individuals preferred less risky vaccines in terms of fewer side effects rather than effectiveness.

Data from our study have also shown that muscle pain around the injection site, fever, problems of blood clots (37.8\%), headache, fatigue, and aching limbs are the major side-effects that healthcare workers in southern Ethiopia perceive to be caused by COVID-19 vaccine. On the other hand, majority $(63.6 \%)$ of the healthcare workers participating in the survey reported that they have experienced muscle pain around the injection site after receiving the COVID-19 vaccine, followed by those who disclosed that they have experienced fatigue $(42 \%)$, headache $(37.2 \%)$, fever $(34.2 \%)$, redness around the injection site $(21.6 \%)$, and swelling around the injection site (17.8\%). Furthermore, it is also indicated that only 3.3\% of the research participants have reported that they have experienced other side-effects that can be labeled as more serious than the types of side-effects discussed above. Kadali et al21 found localized soreness, generalized weakness, myalgia, headache, chills, fever, joint pain and nausea were the most commonly reported symptoms, followed by muscle stiffness or spasm, sweating, dizziness, flushing, feelings of joy/relief/gratitude, brain fogging or reduced mental clarity/attention/concentration, decreased appetite, 
Table 5 Results of Binary Logistic Regression Analysis

\begin{tabular}{|c|c|c|c|c|c|c|c|}
\hline \multirow[t]{2}{*}{ Variables } & \multirow[t]{2}{*}{ Categories } & \multicolumn{3}{|c|}{$\begin{array}{l}\text { Have You Ever Expected } \\
\text { That COVID-19 Vaccine } \\
\text { Will Have Serious and } \\
\text { Life-Threatening Side } \\
\text { Effects? }\end{array}$} & \multirow[t]{2}{*}{ P-value } & \multirow[t]{2}{*}{ OR } & \multirow[t]{2}{*}{ 95\% C.I. } \\
\hline & & Yes & No & Total & & & \\
\hline \multirow[t]{2}{*}{ Sex } & Male & 84 & 84 & 168 & \multirow[t]{2}{*}{0.245} & \multirow[t]{2}{*}{1.373} & \multirow[t]{2}{*}{$0.805-2.341$} \\
\hline & Female & 100 & 80 & 180 & & & \\
\hline Age & & & & & 0.158 & 0.969 & $0.927-1.012$ \\
\hline \multirow[t]{4}{*}{ Marital status } & Never married & 59 & 75 & 134 & \multirow[t]{4}{*}{0.999} & \multirow[t]{4}{*}{$13,058.6$} & \multirow[t]{4}{*}{$0.002-0.015$} \\
\hline & Married & 107 & 101 & 208 & & & \\
\hline & Divorced & 0 & 4 & 4 & & & \\
\hline & Widowed & 2 & 0 & 2 & & & \\
\hline \multirow[t]{5}{*}{ Education } & Primary level & 4 & 3 & 7 & \multirow[t]{5}{*}{$0.006^{* *}$} & \multirow[t]{5}{*}{0.229} & \multirow[t]{5}{*}{$0.080-0.65$} \\
\hline & Secondary level & 4 & 4 & 8 & & & \\
\hline & College diploma & 32 & 33 & 65 & & & \\
\hline & BA/BSc degree & 121 & 119 & 240 & & & \\
\hline & $\mathrm{MA} / \mathrm{Sc} \&$ above & 7 & 21 & 28 & & & \\
\hline \multirow[t]{3}{*}{ Ownership of organization } & Public & 81 & 93 & 174 & \multirow[t]{3}{*}{0.941} & \multirow[t]{3}{*}{1.045} & \multirow[t]{3}{*}{$0.327-3.33$} \\
\hline & Private & 79 & 79 & 158 & & & \\
\hline & Charity & 8 & 8 & 16 & & & \\
\hline \multirow[t]{8}{*}{ Occupation } & Medical doctor & 15 & 17 & 32 & \multirow[t]{8}{*}{0.152} & \multirow[t]{8}{*}{0.416} & \multirow[t]{8}{*}{$0.125-1.383$} \\
\hline & Health officer & 29 & 33 & 62 & & & \\
\hline & Administrative staff & 3 & 5 & 8 & & & \\
\hline & Nurse & 76 & 77 & 153 & & & \\
\hline & Laboratory technician & 10 & 6 & 16 & & & \\
\hline & Pharmacist & 9 & 6 & 15 & & & \\
\hline & Midwife & 16 & 22 & 38 & & & \\
\hline & Other & 10 & 14 & 24 & & & \\
\hline \multirow[t]{3}{*}{ Ever Infected by COVID-19 } & Yes & 26 & 23 & 49 & \multirow[t]{3}{*}{0.070} & \multirow[t]{3}{*}{1.591} & $0.963-2.630$ \\
\hline & No & 82 & 103 & 185 & & & \\
\hline & Not sure & 60 & 54 & 114 & & & \\
\hline Belief in the likelihood of dying from COVID-19 & Yes & 63 & 64 & 127 & $0.58 \mathrm{I}$ & 0.864 & $0.513-1.454$ \\
\hline & No & 105 & 116 & 221 & & & \\
\hline Belief in the effectiveness of COVID-19 vaccine & Yes & 73 & 91 & 164 & 0.443 & 1.209 & $0.744-1.966$ \\
\hline & No & 95 & 89 & 184 & & & \\
\hline
\end{tabular}

(Continued) 
Table 5 (Continued).

\begin{tabular}{|c|c|c|c|c|c|c|c|}
\hline \multirow[t]{2}{*}{ Variables } & \multirow[t]{2}{*}{ Categories } & \multicolumn{3}{|c|}{$\begin{array}{l}\text { Have You Ever Expected } \\
\text { That COVID-1 } 9 \text { Vaccine } \\
\text { Will Have Serious and } \\
\text { Life-Threatening Side } \\
\text { Effects? }\end{array}$} & \multirow[t]{2}{*}{ P-value } & \multirow[t]{2}{*}{ OR } & \multirow[t]{2}{*}{ 95\% C.I. } \\
\hline & & Yes & No & Total & & & \\
\hline \multirow[t]{3}{*}{ History of COVID-19 vaccination } & Completed & 85 & 91 & 176 & \multirow[t]{3}{*}{0.236} & \multirow[t]{3}{*}{1.435} & \multirow[t]{3}{*}{$0.790-2.608$} \\
\hline & Default & 41 & 54 & 95 & & & \\
\hline & Not vaccinated at all & 42 & 35 & 77 & & & \\
\hline
\end{tabular}

Note: $* * \mathrm{P}<0.01$.

Abbreviations: OR, Odds Ratio; C.I., Confidence Interval.

localized swelling at the injection site, decreased sleep quality, itching, tingling, diarrhea, nasal stuffiness, palpitations and/or high heart rate. According to Moss, ${ }^{32}$ the most common side effect is soreness at the site of injection, fatigue, headache, muscle aches, chills, joint pain, and possibly some fever. Moreover, Kaur et $\mathrm{al}^{23}$ argued that the most common adverse events observed with the COVID-19 vaccines were tachycardia, flushing, hypertension, hypotension and peripheral coldness. Reports from $\mathrm{DW}^{33}$ indicated that only typical vaccination reactions, such as pain at the injection site, muscle pain, headache and fatigue occurred with the vaccine from AstraZeneca and it is normal to have certain reactions after a vaccination within three (3) days of vaccination. Although empirical findings are absent, several cases of death of people who have been vaccinated are being reported through public sites and mass media, which create and increase public doubts about the safety of the vaccine and highly affect current mass vaccination campaigns. ${ }^{12}$

\section{Limitations}

With all its strong sides, the study would have better been somewhat improved had it considered certain methodological concerns. Although AstraZeneca has been the vaccine that most people in Ethiopia have received, other brands of COVID-19 vaccine such as Johnson and Johnson were also imported later after we had already started data collection. For this reason, we were able to address the side-effects of AstraZeneca vaccine. Nevertheless, it would have been better had we examined the different side-effects of various brands of COVID-19, including the length of time taken during recovery from the side-effects of these different types of vaccines.
Furthermore, people's perceptions and expectations about the side-effects of COVID-19 vaccine could have been better studied with rich and deep data that can be obtained using qualitative research approach. Therefore, a mixed research approach could have better benefited from this study had we supplemented the quantitative data with a qualitative one. Thus, subsequent studies on the topic at hand can better address the issue if the above concerns are well addressed.

\section{Conclusion}

The results of the study at hand demonstrated that about half of the healthcare workers in southern Ethiopia are not fully vaccinated. It has also been indicated that safety issues have remained a major concern among the study population when it comes to reasons for not receiving COVID-19 vaccine. It should be pointed out that Ethiopia cannot meet the vaccination demands of even half of its population due to economic reasons. Though it may not be equally susceptible, other societal groups in Ethiopia that are highly vulnerable to COVID-19 infection have still continued to demand the vaccine, perhaps mainly as a result of the emergence of new COVID-19 variants. While only the healthcare workers and few others with special cases, such as elderlies with chronic illnesses, have got the priority of getting vaccinated, it has been observed that not all of them are vaccinated. Moreover, while the expectations of most of the healthcare workers regarding the side-effects of the vaccine are parallel to the normal reactions of the vaccine, a significant proportion of the study participants have reported that they perceive COVID-19 vaccine will have serious and life-threatening side-effects. Furthermore, a quarter of them disclosed that 
they hesitated to receive the vaccine due to fear of such side-effects. Therefore, the Ministry of health and other concerned government bodies should create further awareness on COVID-19 vaccine and related safety issues.

\section{Data Sharing Statement}

The data used to support the findings of this study are available from the corresponding author upon reasonable request.

\section{Ethics Approval and Consent to Participate}

The study was evaluated and approved by the Ethics Approval Committee of Wolaita Sodo University (WSUHSC/1527/14). Research participants were first informed about the purpose of the research, including what role is expected from their side. Both verbal and written consents were gained from all research participants. In addition, a formal letter was obtained from the College of Social Science and Humanities of Wolaita Sodo University. This study was conducted in accordance with the relevant guidelines.

\section{Disclosure}

The authors declare that there are no conflicts of interest in this work.

\section{References}

1. Papagiannis D. The lack of vaccine in the recent COVID-19 pandemic and the silence of anti-vaccination activists. Hellenic J Nurs. 2020;59 (4):348-352.

2. Deml MJ, Jafflin K, Merten S, et al. Determinants of vaccine hesitancy in Switzerland: study protocol of a mixed-methods national research programme. BMJ Open. 2019;9(11):e032218. doi:10.1136/bmjopen2019-032218

3. Yaqob O, Clarke CS, Sevdalis N, Chataway J. Attitudes to vaccination: a critical review. Soc Sci Med. 2014;112:1-11. doi:10.1016/j. socscimed.2014.04.018

4. Nzaji KM, Ngombe KL, Mwamba NG, et al. Acceptability of vaccination against Covid-19 among healthcare workers in the Democratic Republic of the Congo. Pragmat Obs Res. 2020;112:103-109. doi:10.2147/POR.S271096

5. Paterson P, Paterson P, Meurice F, Stanberry LR, Glismann S, Rosenthal SL. Vaccine hesitancy and healthcare providers. Vaccine. 2016;34(52):6700-6706. doi:10.1016/j.vaccine.2016.10.0425

6. Smith L, Amlot R, Weinman J, Yiend J, Rubin J. A systematic review of factors affecting vaccine uptake in young children. Vaccine. 2017;35 (45):6059-6069. doi:10.1016/j.vaccine.2017.09.046

7. Qattan AMN, Alshareef N, Alsharqi O, Al Rahahleh N, Chirwa GC, Al-Hanawi MK. Acceptability of a COVID-19 vaccine among healthcare workers in the Kingdom of Saudi Arabia. Front Med. 2021;8:644300. doi:10.3389/fmed.2021.644300

8. Kukreti S, Lu M-Y, Lin Y-H, et al. Willingness of Taiwan's healthcare workers and outpatients to vaccinate against COVID-19 during a period without community outbreaks. Vaccines. 2021;9(3):246. doi: $10.3390 /$ vaccines 9030246
9. Paudel S, Palaian S, Shankur PR, Subedi N. Risk perception and hesitancy toward COVID-19 vaccination among healthcare workers and staff at a medical college in Nepal. Risk Manag Healthc Policy. 2021;14:2253-2261. doi:10.2147/RMHP.S310289

10. Roy B, Kumar V, Venkatesh A. Health care workers' reluctance to take the COVID-19 vaccine: a consumer marketing approach to identifying and overcoming hesitancy. NEJM Catalyst Innov Care Delivery. 2020;1(6). doi:10.1056/CAT.20.0676

11. Paltiel AD, Schwartz JL, Zheng A, Walensky RP. Clinical outcomes of a COVID-19 vaccine: implementation over efficacy. Health Aff. 2021;40(1):42-52. doi:10.1377/hlthaff.2020.02054

12. Kounis NG, Koniari I, de Gregorio C, et al. Allergic reactions to current available COVID-19 vaccinations: pathophysiology, causality, and therapeutic considerations. Vaccines. 2021;9(3):221. doi: $10.3390 /$ vaccines 9030221

13. Herve C, Laupeze B, Giudice GD, Didierlaurent AM, Silva F. The how's and what's of vaccine reactogenicity. NPJ Vaccines. 2019;4(1). doi:10.1038/s41541-019-0132-6

14. Hatmal MM, Al-Hatamleh MAI, Olaimat AN, et al. Side effects and perceptions following COVID-19 vaccination in Jordan: a randomized, cross-sectional study implementing machine learning for predicting severity of side effects. Vaccines. 2021;9(6):556. doi:10.3390/ vaccines 9060556

15. Science. 'It's a very special picture.' Why vaccine safety experts put the brakes on AstraZeneca's COVID-19 vaccine; 2021. Available from: https://www.sciencemag.org/news/2021/03/it-s-very-specialpicture-why-vaccine-safety-experts-put-brakes-astrazeneca-scovid19? fbclid=IwAR342kTxQHfUMQa9RTZnFcB_MweG0_ Ifgcu4syAfzOHhTuIuLmNe9D4KI5c. Accessed December 3, 2021.

16. The New York Times. A few covid vaccine recipients developed a rare blood disorder; 2021. Available from https://www.nytimes.com/ 2021/02/08/health/immune-thrombocytopenia-covid-vaccine-blood. html. Accessed December 3, 2021.

17. Nguyen KH, Srivastaz A, Razzaghi H, et al. COVID. COVID-19 vaccination intent, perceptions, and Reasons for Not vaccinating among groups prioritized for early vaccination - United States, September and December 2020. MMWR Morb Mortal Wkly Rep. 2021;70(6):217-222. doi:10.15585/mmwr.mm7006e3.

18. Ossato A, Tessari R, Trabucchi C, Zuppini T, Realdon N, Marchesini F. Comparison of medium-term adverse reactions induced by the first and second dose of mRNA BNT162b2 (Comirnaty, Pfizer-BioNTech) vaccine: a post-marketing Italian study conducted between 1 January and 28 February 2021. Eur J Hosp Pharm. 2021;28(1):1-6. doi:10.1136/ejhpharm-2021-002933

19. Polack FP, Thomas SJ, Kitchin N, et al.; C4591001 Clinical Trial Group. Safety and efficacy of the BNT162b2 mRNA Covid-19 vaccine. $N$ Engl J Med. 2020;383(27):2603-2615. PMID: 33301246; PMCID: PMC7745181. doi:10.1056/NEJMoa2034577

20. Shimabuko T, Kim S, Myers T, et al. Preliminary findings of mRNA Covid-19 vaccine safety in pregnant persons. $N$ Engl $J$ Med. 2021;384(24):2273-2282. doi:10.1056/NEJMoa2104983

21. Kadali RK, Janagama R, Peruru S, Malayala SV. Side effects of BNT162b2 mRNA COVID-19 vaccine: a randomized, cross-sectional study with detailed self-reported symptoms from healthcare workers. Int $J$ Infect Dis. 2021;106:376-381. doi:10.1016/j. ijid.2021.04.047

22. Klugar M, Riad A, Mekhemar M, et al. Side effects of mRNA-based and viral vector-based COVID-19 vaccines among German healthcare workers. Biology. 2021;10(8):752. doi:10.3390/ biology 10080752

23. Kaur RJ, Dutta S, Charan J, et al. Cardiovascular adverse events reported from COVID-19 vaccines: a study based on WHO database. Int J Gen Med. 2021;9:3909-3927. doi:10.2147/IJGM.S324349

24. AllAfrica. Ethiopia receives the first astra zeneca Covid-19 vaccine; 2021. Accessed from: https://allafrica.com/stories/202103070285. html. Accessed December 3, 2021. 
25. Zewude B, Belachew A. Intention to receive the second round of COVID-19 vaccine among healthcare workers in Eastern Ethiopia. Infect Drug Resist. 2021;14:3071-3082. doi:10.2147/IDR.S326055

26. Zewude B, Habtegiorgis T. Willingness to take COVID-19 vaccine among people most at risk of exposure in Southern Ethiopia. Pragmat Obs Res. 2021;12:37-47. doi:10.2147/POR.S313991

27. Woyessa AH, Oluma A, Palanichamy T, et al. Predictors of healthcare workers' unwillingness to continue working during the peak of COVID-19 in Western Ethiopia: an extended parallel-process model study. Risk Manag Healthc Policy. 2021;14:1165-1173. doi:10.2147/ RMHP.S288003

28. Hailu D, Benayew M, Liknaw T, et al. Occupational health safety of health professionals and associated factors during COVID-19 pandemics at North Showa Zone, Oromia Regional State, Ethiopia. Risk Manag Healthc Policy. 2021;14:1299-1310. doi:10.2147/RMHP.S292830

29. Pataka A, Kotoulas S, Stefanidou E, et al. Acceptability of healthcare professionals to get vaccinated against COVID-19 TwoWeeks before initiation of national vaccination. Medicina. 2021;57(6):611. doi:10.3390/medicina57060611
30. Unroe KT, Evans R, Weaver L, Rusynaik D, Blackburn J. Willingness of Long-term care staff to receive a COVID-19 vaccine: a single state survey. J Am Geriatr Soc. 2021;69(3):593-599. doi:10.1111/jgs.17022

31. Cerda AA, García LY. Hesitation and refusal factors in individuals' decision-making processes regarding a coronavirus disease 2019 vaccination. Front Public Health. 2021;9:626852.

32. Moss WJ. Side effects and COVID-19 vaccines: What to expect; Johns Hopkins Bloomberg school of public health; 2020. Available from: https://www.jhsph.edu/covid-19/articles/side-effects-andcovid-19-vaccines-what-to-expect.html. Accessed December 3, 2021.

33. Welle D. COVID-19: risks and side effects of vaccination; 2021. Available from: https:/www.dw.com/en/covid-19-risks-and-sideeffects-of-vaccination/a-56136620. Accessed December 3, 2021.

\section{Publish your work in this journal}

Pragmatic and Observational Research is an international, peerreviewed, open access journal that publishes data from studies designed to reflect more closely medical interventions in realworld clinical practice compared with classical randomized controlled

Submit your manuscript here: http://www.dovepress.com/pragmatic-and-observational-research-journal trials (RCTs). The manuscript management system is completely online and includes a very quick and fair peer-review system. Visit $\mathrm{http} / / / \mathrm{www}$.dovepress.com/testimonials.php to read real quotes from published authors. 